Atıf İçin: Karaçelik AA, Efe D, Çakır V, Bıyıklığlu Z, 2021. Aksiyal Disübstitüe Silisyum Ftalosiyaninlerin Biyolojik Aktivitelerinin Belirlenmesi. Iğdır Üniversitesi Fen Bilimleri Enstitüsü Dergisi, 11(2): 1302-1310.

To Cite: Karaçelik AA, Efe D, Çakır V, Bıyıklığlu Z, 2021. Determination of Biological Activities of Axially Disubstituted Silicon Phthalocyanines. Journal of the Institute of Science and Technology, 11(2): 1302-1310.

\title{
Aksiyal Disübstitüe Silisyum Ftalosiyaninlerin Biyolojik Aktivitelerinin Belirlenmesi
}

\section{Ayça Aktaş KARAÇELIKK ${ }^{1 *}$, Derya EFE², Volkan ÇAKIR ${ }^{3}$, Zekeriya BIYIKLIOĞLU $^{4}$}

ÖZET: Bu çalışmada daha önce sentezlenen eksenel ([3- (dimetilamino) fenoksi] propanooksi) ve ([3- (dietilamino) fenoksi] propanooksi) ikameli silisyum ftalosiyaninlerin (DM-C3-Si ve DE-C3-Si) biyolojik aktivitelerinin [sı̆̆ır karbonik anhidraz (bCA) inhibisyonu, antioksidan ve antibakteriyel] değerlendirilmesi amaçlandı. CA inhibisyon aktivitesi, esteraz aktivitesi ile belirlendi. Antioksidan aktivite, iki yaygın yöntem olan 2,2-difenil-1-pikrilhidrazil (DPPH•) radikal temizleme ve demir iyon (III) indirgeme / antioksidan güç (FRAP) metotları ile belirlendi. Antibakteriyel aktivite, üç Gram-negatif ve üç Grampozitif bakteriye karşı disk difüzyon yöntemi ile belirlendi. Sonuçlara göre, DE-C3-Si silisyum ftalosiyanin, standart CA inhibitörü sülfanilamide kıyasla 2333 nM IC I0 $_{5}$ değeriyle yaklaşık iki kat daha yüksek CA inhibitör aktivitesi gösterdi. Antioksidan sonuçlarına göre, silisyum ftalosiyaninler standart $\mathrm{C}$ vitamininden daha yüksek antioksidan aktivite gösterdi (DPPH• radikal temizleme $\mathrm{SC}_{50}$ değerleri: DM-C3-Si: $0.0199 \mathrm{mg} \mathrm{mL} \mathrm{L}^{-1}$ ve DE-C3-Si: $0.0232 \mathrm{mg} \mathrm{mL}^{-1}$, FRAP TEAC değerleri: DM-C3-Si: $232 \mu \mathrm{M}$ ve DE-C3-Si: $73 \mu \mathrm{M}$ ). Bu bileşiklerin antibakteriyel aktivitesinin Gram-negatif ve Grampozitif bakterilere karşı çok az olduğu gözlendi. Sonuç olarak, silisyum ftalosiyaninler, biyolojik aktiviteleri nedeniyle yeni CA inhibitörlerinin keşfinde ve gıdalarda büyük kullanım potansiyeline sahiptir.

Anahtar Kelimeler: Sı̆̆ır karbonik anhidraz, inhibitör, biyolojik aktivite, silisyum ftalosiyaninler

\section{Determination of Biological Activities of Axially Disubstituted Silicon Phthalocyanines}

\begin{abstract}
In this study, previously synthesized axially ([3-(dimethylamino)phenoxy]propanoxy) and ([3(diethylamino)phenoxy]propanoxy) substituted silicon phthalocyanines (DM-C3-Si and DE-C3-Si) were aimed to evalute biological activities [bovine carbonic anhydrase (bCA) inhibition, antioxidant, and antibacterial]. CA inhibition activity was determined by esterase activity. The antioxidant activity was determined by two common methods, 2,2-diphenyl-1picrylhydrazyl (DPPH•) radical scavenging and ferric ion (III) reducing / antioxidant power (FRAP) assay. The antibacterial activity was determined by the disk diffusion method against three Gram-negative and three Gram-positive bacteria. According to the results, DE-C3-Si silicon phthalocyanin showed approximately twice as high CA inhibitory activity with $\mathrm{IC}_{50}$ value of $2333 \mathrm{nM}$ compared with the standard CA inhibitor sulfanilamide. According to the antioxidant studies, the silicon phthalocyanines showed higher antioxidant activity than the standard vitamin $\mathrm{C}$ ( $\mathrm{SC}_{50}$ values of DPPH• scavenging activity: $0.0199 \mathrm{mg} \mathrm{mL}^{-1}$ for DM-C3-Si and $0.0232 \mathrm{mg} \mathrm{mL}^{-1}$ for DE-C3-Si, TEAC values of FRAP: $232 \mu \mathrm{M}$ for DM-C3-Si and $73 \mu \mathrm{M}$ for DE-C3-Si). It was observed that antibacterial activity of these compounds were exellent slight against Gramnegative and Gram-positive bacteria. As a result, silicon phthalocyanines have great potential of use in the discovery of new $\mathrm{CA}$ inhibitors and in food due to their biological activities.
\end{abstract}

Keywords: Bovine carbonic anhydrase, inhibitor, biological activity, silicon phthalocyanines

\footnotetext{
${ }^{1}$ Ayça Aktaş KARAÇELİK (Orcid ID: 0000-0001-5381-2924), Giresun Üniversitesi, Espiye Meslek Yüksekokulu, Gıda İşleme Bölümü, Giresun, Türkiye

${ }^{2}$ Derya EFE (Orcid ID: 0000-0003-3554-1790), Giresun Üniversitesi, Espiye Meslek Yüksekokulu, Bitkisel ve Hayvansal Üretim Bölümü, Giresun, Türkiye

${ }^{3}$ Volkan ÇAKIR (Orcid ID: 0000-0002-5817-0817), Giresun Üniversitesi, Espiye Meslek Yüksekokulu, Tıbbi Hizmetler ve Teknikler Bölümü, Giresun, Türkiye

${ }^{4}$ Zekeriya BIYIKLIOĞLU ( Bölümü, Trabzon, Türkiye
}

*Sorumlu Yazar/Corresponding Author: Ayça Aktaş KARAÇELİK, e-mail: ayca.aktas@giresun.edu.tr 


\section{GİRIŞ}

Metalsiz ve metalli ftalosiyaninler günümüzde boyar madde (Yongde ve Zhenguo, 2006), katalizör (Dini ve ark, 2003), fotodinamik terapi (PDT) (Kluson ve ark, 2008), elektrokimyasal ve optik gaz sensörleri (Sarkı ve ark, 2019), CD-ROM ve DVD-ROM teknolojilerinde (Bekaroğlu, 1996) kullanım olanağı bulmuştur. Fakat ftalosiyaninlerin yukarıda bahsedilen ve daha birçok uygulama alanında kullanımını kısıtlayan veya düşük etkinlik çıkmasına neden olan dezavantajları vardır. Bunlar yaygın organik çözücüler içerisinde düşük çözünürlük ve agregasyon (istiflenme) olarak bilinmektedir (Ünlü ve ark, 2008). Bu iki önemli dezavantaj merkez atomun aksiyal pozisyonlarda ligand bulundurmasıla aşılabilir. Bu durumda çözelti içerisinde ftalosiyanin moleküllerinin birbirine yaklaşması engellenerek hem çözünürlük arttırılır hem de agregasyon önlenebilir. Aksiyal pozisyonlarda ligand ihtiva eden ftalosiyaninlerin en iyi örneği substitüe silisyum ftalosiyaninlerdir. Yüksek çözünürlük, düşük agregasyon ve bu ikisine bağlı olarak yüksek etkinlik alabilmek adına bu çalışmada aksiyal disubstitüe silisyum ftalosiyaninler tercih edilmiştir.

Karbonik anhidraz (CA), temel olarak karbondioksitin $\left(\mathrm{CO}_{2}\right)$ bikarbonata $\left(\mathrm{HCO}_{3}{ }^{-}\right)$tersinir dönüşümünden sorumlu olan ve eritrositleri de içine alan pek çok hücre tipinde bulunan çinko metaloenzimlerdir. Omurgalılarda, farklı hücresel lokalizasyonlar ve doku dağılımları temelinde 16 farklı (CAI-XIV) izoenzimi tanımlanmıştır (Supuran, 2010). Bu izoenzimler pH regülasyonu, $\mathrm{CO}_{2}$ homeostazı, kemik resorpsiyonu, kalsifikasyon, tümör oluşumu ve diğer birçok metabolik süreç dahil olmak üzere çeşitli fizyolojik süreçlerde yer alır (Pastarekova ve ark, 2004). Bazı CA izoenzimlerin aşırı ekspresyonu sonucu glokom, ateroskleroz, tümör oluşumu ve obezite gibi fizyolojik bozukluklar ortaya çıkabilir (Supuran ve Scozzafava, 2007). Aynı zamanda CA enziminin aktivitesindeki eksiklik alzheimer hastalığına neden olabilir (Alterio ve ark, 2012). Klinikte halen kullanılan sülfonamid/sülfamat türevi inhibitörleri olan asetazolamid ve etokszolamid gibi çok sayıda CA inhibitörü vardır. Son zamanlarda da birçok araştırma grubu tarafından CA'nın inhibitörleri ve aktivatörlerini tanımlamak için yeni moleküller araştırılmaktadır (McKenna ve Supuran, 2014). Ftalosiyanin türevleri, bazı enzim inhibitörlerinin gelişimi için potansiyel öncü bileşikler olarak gösterilmiştir (Zhang ve ark, 2008; Karaçelik ve ark, 2021).

Oksidatif stres, reaktif oksijen türleri (ROS) ve antioksidan savunmalar arasındaki dengesizliğin bir sonucudur. Bu oksidatif stres bir dizi hücre fonksiyonu üzerinde hücre ölümüyle sonuçlanan çeşitli bozukluklarına neden olabilir. Dolayısıyla, antioksidanlar oksidatif hasara karşı önemli inhibitörlerdir. Bir veya daha fazla reaktif türle katalitik veya sitokiyometrik olarak reaksiyona girebilen sentetik ve doğal bileşikler geliştirilmiş. Bu konuda biyolojik özelliklere sahip farklı fonksiyonel grupları olan yeni ftalosiyanin bileşiklerinin sentezi ve karakterizasyonu araştırılmaktadır (Yıldırım ve ark, 2017). Ayrıca ftalosiyanin moleküllerinin merkezinde bulunan metal iyonu ve ikame edilmiş gruplara göre farklı antimikrobiyal ve antioksidan özellikleri sergilediği bulunmuştur (Farajzadeh ve ark, 2019; Yıldırım ve ark, 2017; Demirkapi ve ark, 2014).

Antibiyotikler başta olmak üzere antibakteriyel bileşikler son zamanlarda yaygın olarak kullanılmaktadır. Ancak, kullanılan bu bileşikler antibakteriyellere karşı dirençli mikroorganizmaların açığa çıkmasına neden olmaktadır. Bu bileşiklerin doğal döngüde görevli olan mikroorganizmaları öldürmesi veya sayılarını azaltması da bir diğer yan etkisidir (Efe, 2020). Son zamanlarda, birçok araştırmacı yan etkisi olmayan yeni antibakteriyel ajanlar bulmak üzerine yoğunlaşmıştır. Bu bağlamda, yeni sentezlenen silisyum ftalosiyaninler bu ihtiyacı karşılayabilecek umut verici bileşiklerdir (Basappa ve ark, 2015). 
$\mathrm{Bu}$ bilgiler 1şığında mevcut çalışmada, daha önce elektropolimerizasyon ve agregasyon özelliklerinin incelenmesi amaciyla sentezlenmiş olan DM-C3-Si ve DE-C3-Si silisyum ftalosiyanin bileşiklerinin (Bıyıklığlu ve Alp, 2016) ilk defa biyolojik aktivitelerinin (bCA inhibisyon, antioksidan ve antibakteriyel) değerlendirilmesi amaçlanmıştır.

\section{MATERYAL VE METOT}

\section{Kimyasal Sentez}

([3-(dimetilamino)fenoksi]propanoksi) ve ([3-(dietilamino)fenoksi]propanoksi) silisyum ftalosiyaninler (DM-C3-Si ve DE-C3-Si) B1yıklıoglu ve ark. (B1yıklığlu ve Alp, 2016) literatürüne göre sentezlendi. Tüm çözücüler Merck firmasından satın alındı ve kullanılmadan önce destillendi. Reaktantlar yüksek saflıkta ve çeşitli ticari şirketlerden satın alındı. Reaksiyonlar susuz ortamda azot gazı atmosferi altında gerçekleştirildi.

\section{Bis ([3-(dimetilamino)fenoksi]propanoksi) ftalosiyanato silisyum (IV) Sentezi (DM-C3-Si)}

Silisyum ftalosiyanin diklorid (150 mg, $0.24 \mathrm{mmol}$ ), 3-[3-(dimetilamino)fenoksi]propan-1-ol (94 mg, $0.48 \mathrm{mmol}) 15 \mathrm{~mL}$ kuru toluen içerisine eklendi. Karışım 10 dakika azot gazı atmosferinde karıştırıldı ve üzerine sodyum hidrid (11.52 mg, $0.48 \mathrm{mmol}$ ) ilave edildi. Bu karışım 24 saat boyunca riflaks edildi. Süre sonunda karışım oda sıcaklığına soğutuldu ve çözücü düşük basınç altında buharlaştırıldı. Elde edilen katı ham ürün sabit faz olarak alüminyum oksit hareketli faz olarak $\mathrm{CHCl}_{3}: \mathrm{CH}_{3} \mathrm{OH}$ (100:2) çözücü sistemi kullanılan kolon kromatografisi yöntemi ile saflaştırıldı. Reaksiyona ait sentez şeması Şekil 1'de verilmiştir (Bıyıklığlu ve Alp, 2016).

\section{Bis ([3-(dietilamino)fenoksi]propanoksi) ftalosiyanato silisyum (IV) Sentezi (DE-C3-Si)}

Bileşik (DE-C3-Si), 3-[3-(dimetilamino)fenoksi]propan-1-ol yerine 3-[3(dietilamino)fenoksi]propan-1-ol kullanılarak (DM-C3-Si) bileşiği ile aynı kimyasal yöntem kullanılarak sentezlendi ve saflaştırıldı. Reaksiyona ait sentez şeması Şekil 1'de verilmiştir (Bıyıklığlu ve Alp, 2016).

\section{DPPH• Radikal Temizleme Aktivitesi}

Numunelerin antioksidan aktivitesi, Cuendet ve arkadaşları (Cuendet ve ark, 1997) tarafından geliştirilen DPPH• radikal temizleme yöntemi kullanılarak test edilmiştir. Öncelikle $0.1 \mathrm{mM} \mathrm{DPPH}$ çözeltisi metanol içinde taze ve günlük olarak hazırlandı. Numunelerin çalışma konsantrasyonları, yaklaşık \%50 temizleme sağlayan konsantrasyonlarla sonuç gösterecek şekilde ayarlandı. Kısaca yöntemde, $0.75 \mathrm{~mL}$ numunelerin çeşitli konsantrasyonları, $0.75 \mathrm{~mL} 0.1 \mathrm{mM}$ metanolik DPPH çözeltisi ile karıştırıldı. Oda sıcaklığında 50 dakikalık inkübasyon süresinden sonra, absorbans $517 \mathrm{~nm}$ 'de saf suya karşı okundu. DPPH• radikal temizleme aktivitesi, DPPH• radikalinin \%50 temizlenmesine neden olan numune konsantrasyonu $\left(\mathrm{SC}_{50}\right)$ olarak ifade edildi. Düşük $\mathrm{SC}_{50}$ değerleri daha yüksek radikal temizleme potansiyelini gösterir. Sonuçlar standart antioksidanlar BHT, Troloks ve C vitamini ile karşılaştırıldı. Reaksiyon karışımının daha yüksek emilimi, daha düşük DPPH• radikal temizleme aktivitesini gösterir.

\section{Demir İndirgeme / Antioksidan Güç (FRAP) Yöntemi}

FRAP, orijinal olarak Oyaizu (1986) tarafından geliştirilmiş olup toplam indirgeme potansiyelinin dolaylı olarak belirlendiği bir yöntemdir (Oyaizu, 1986). Yöntem, $\mathrm{Fe}^{+3}$ 'ün $\mathrm{Fe}^{+2}$,ye indirgenmesi ile elde edilen renk değişikliğinin 595 nm'de ölçülmesine esasına dayanır. Öncelikle deneyde kullanılan numunelerin konsantrasyonu $0.04 \mathrm{mg} \mathrm{mL}^{-1}$, ye (DM-C3-Si için $43.0 \mu \mathrm{M}$ ve DE-C3-Si $40.5 \mu \mathrm{M}$ ) seyreltildi. Ardından FRAP reaktifi, pH 3.6' da 300 mM asetat tamponu, $10 \mathrm{mM}$ [2,4,6-Tris(2-pyridyl)s-triazine (TPTZ)'nin $40 \mathrm{mM} \mathrm{HCl}$ 'deki çözeltisi ve $20 \mathrm{mM} \mathrm{Fe} \mathrm{Cl}_{3} .6 \mathrm{H}_{2} \mathrm{O}$ çözeltileri sırasıyla 10:1:1 
oranında karıştırılarak taze hazırlandı. Daha sonra $50 \mu \mathrm{L}$ numune, $1.5 \mathrm{~mL}$ FRAP reaktifi ile karıştırıldı. Oda sıcaklığında 20 dakikalık inkübasyonun ardından absorbans 595 nm' de okundu. Yöntemde standart olarak kullanılan Troloks'un 62.5-1000 $\mu \mathrm{M}$ aralığındaki konsantrasyonları kullanılarak absorbans ölçümlerine dayalı kalibrasyon grafiğgi çizildi. Numunelerin aktivitesi, bu grafik kullanılarak antioksidan aktivite Troloks eşdeğeri antioksidan kapasite (TEAC, $\mu \mathrm{M}$ ) olarak ifade edildi.

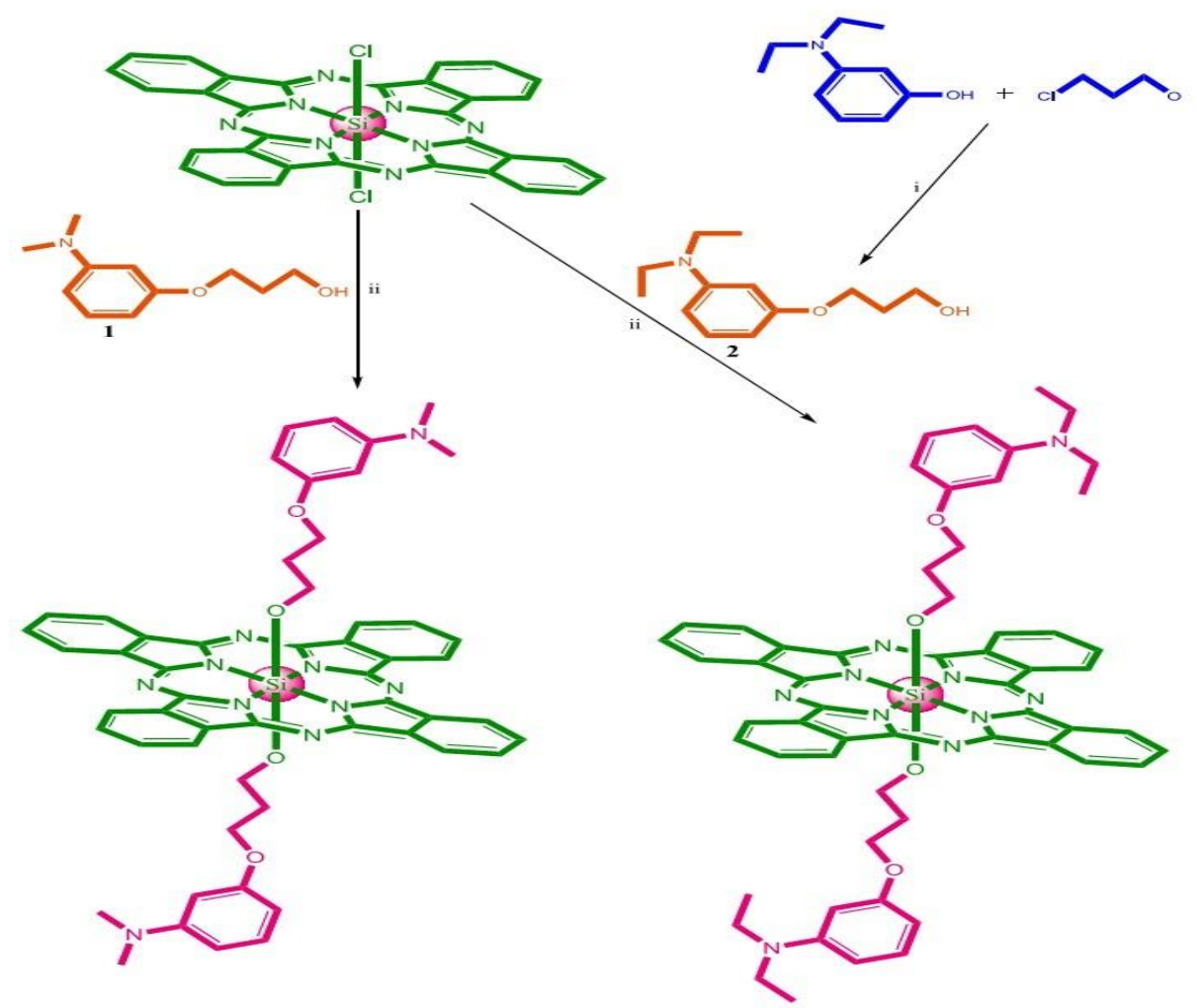

Şekil 1: Aksiyal disübstitüe silisyum ftalosiyaninlerin (DM-C3-Si ve DE-C3-Si) sentez şemas1. (i) $\mathrm{NaOH}, \mathrm{EtOH}, 80^{\circ} \mathrm{C}$. (ii) Toluene, $\mathrm{NaH}, 120^{\circ} \mathrm{C}$ (B1yıklığlu ve Alp, 2016).

\section{Sığır Karbonik Anhidraz (bCA) İnhibisyon Aktivitesinin Belirlenmesi}

Yöntem karbonik anhidrazın esteraz aktivitesine sahip olması esasına dayanmaktadır. Buna göre enzim aktivitesi, $348 \mathrm{~nm}$ 'de $p$-nitrofenole veya $p$-nitrofenolata hidrolize olan $p$-nitrofenil asetatın spektrofotometrik olarak ölçülmesi ile belirlenmektedir (Armstrong ve ark, 1966). Standart bCA enzimi

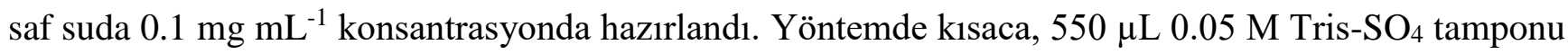
(pH: 7.4), $150 \mu \mathrm{L}$ enzim çözelti, $50 \mu \mathrm{L}$ numune çözeltilerini içeren karışıma $750 \mu \mathrm{L} p$-nitrofenil asetat ( $3 \mathrm{mM}$ ) eklenip vortekslendi. Sonra karışımın 348 nm'deki absorbansı 30 dakika boyunca kaydedildi. Sonuçlar numune içermeyen kontrol ve enzim içermeyen kör testlerle karşılaştırmalı olarak değerlendirildi. Her bir numunenin beş farklı konsantrasyonunda esteraz aktivite ölçümü yapıldı. Sığır karbonik anhidraz (bCA) enzimi üzerine inhibisyon etkisine sahip olan her bir numune için Aktivite(\%)İnhibitör konsantrasyonu [I] grafikleri çizilerek \%50 inhibisyona sebep olan inhibitör konsantrasyon ( $\left.\mathrm{IC}_{50}\right)$ değerleri hesapland.

\section{Antibakteriyel Test}

DM-C3-Si ve DE-C3-Si numuneleri $0.01 \mathrm{mg} \mathrm{mL}^{-1}, 0.02 \mathrm{mg} \mathrm{mL}^{-1}, 0.03 \mathrm{mg} \mathrm{mL}^{-1}$ ve $0.04 \mathrm{mg} \mathrm{mL}^{-1}$ olacak şekilde \%100'lük DMSO kullanılarak hazırlandı. Çalışmamızda üç tane Gram-negatif (Acinetobacter baumannii ATCC BAA-747, Klebsiella pneumoniae ATCC 13883, Citrobakter freundii ATCC 43864) ve üç tane Gram-pozitif (Staphylococcus aureus ATCC29213, Bacillus subtilis 
ATCC 6633, Staphylococcus epidermidis ATCC 12228) bakteri kullanıld1. Antibakteriyel aktivite disk difüzyon yöntemi ile değerlendirildi. Steril bir eküvyon çubuğu ile $10^{6} \mathrm{kob} \mathrm{mL}^{-1}$ içeren her bir bakteri solüsyonundan ayrı ayrı petri kaplarında Müller Hinton Agar (MHA) medium üzerine yayma yapıldı. 6mm'lik standart disklere test edilen bileşiklerin her bir konsantrasyonu ayrı ayr1 $10 \mu \mathrm{L}$ emdirilerek ve bakterileri ile inokule edilmiş agar üzerine yerleştirildi. Negatif kontrol olarak numunelerin dilüsyonunda kullanılan \%100'luk DMSO kullanıldı. Pozitif kontrol olarak sulbaktam (SCF) (30 $\mu \mathrm{g}$ /disk) diskleri kullanıld1. Hazırlanan deney düzenekleri $37^{\circ} \mathrm{C}$ 'de 24 saat inkübe edildi. Belirtilen süre sonunda bileşiklerin emdirildiği standart disklerin ve antibiyotik diskinin çevresinde oluşan şeffaf inhibisyon zon çapları ölçülerek kaydedildi. Her bir deney üç tekrarlı olarak gerçekleştirildi (Efe, 2019).

\section{BULGULAR VE TARTIŞMA}

3-dimetilaminofenoksipropanoksi ve 3-dietilaminofenoksipropanoksi silisyum ftalosiyaninler (DM-C3-Si ve DE-C3-Si) Bıyıklıglu ve ark. (Bıyılığlu ve Alp, 2016) litaretürüne göre sentezlenmiştir. DM-C3-Si ve DE-C3-Si bileşiklerinin antioksidan aktivitesi FRAP ve DPPH• radikal temizleme yöntemleri kullanılarak test edilmiştir (Çizelge 1). Çizelge 1'e göre $\mathrm{SC}_{50}$ değeri düşük olan DM-C3-Si kodlu bileşik $\left(0.0199 \mathrm{mg} \mathrm{mL}^{-1}\right)$ en yüksek DPPH• radikal temizleme aktivitesine sahip iken $\mathrm{SC}_{50}$ değeri büyük olan DE-C3-Si kodlu bileşik $\left(0.0232 \mathrm{mg} \mathrm{mL}^{-1}\right)$ ise en düşük antioksidan aktiviteye sahiptir. Numunelerin standartlarla karşılaştırılmasında, Numuneler Troloks ve BHT'den daha düşük aktiviteye sahip olup C vitamininden ise daha yüksek antioksidan aktiviteye sahip oldukları belirlenmiştir. FRAP test sonuçları DPPH• radikal temizleme aktivite sonuçları ile paralellik göstermektedir. Buna göre DM-C3-Si kodlu ftalosiyanin bileşiği FRAP değeri $232 \mu \mathrm{M}$ TEAC değeri ile DE-C3-Si'den daha yüksek antioksidan aktiviteye sahiptir. Çalışılan konsantrasyonlardaki silisyum ftalosiyaninlerin TEAC değerleri Troloks'tan 1.78 ila 5.39 kat daha yüksek bulundu. Literatürde ftalosiyaninlerin antioksidan aktivitesi hakkında çok sayıda araştırma yapılmış olsa da, silisyum ftalosiyaninlerin antioksidan aktivitesi hakkında çok az araştırma bulunmaktadır. Bu yüzden sonuçlar ftalosiyaninler ile karşılaştırıldığında, silisyum ftalosiyaninlerin bazı ftalosiyaninlerden daha iyi antioksidan aktiviteye sahip olduğu görüldü (Ağırtaş ve ark, 2018; Günsel ve ark, 2019; Günsel ve ark, 2020; Unluer ve ark, 2019). Bu bağlamda, bu çalışmanın yeni antioksidan bileşiklerin keşfinde yararlı olacağı düşünülmüştür.

$\mathrm{Bu}$ çalışmada aynı zamanda daha önceden sentezlenen silisyum ftalosiyaninlerin bCA enzimi üzerindeki inhibitör etkileri değerlendirilip sonuçlar Çizelge 1'de IC $_{50}$ değerleri olarak verilmiştir. Düşük $\mathrm{IC}_{50}$ değeri yüksek bCA inhibisyonunu göstermektedir. Silisyum ftalosiyaninlerin ilgili fonsiyonel grupları (metil ve etil) bCA enzim inhibisyonu üzerinde farklı etkiler göstermiştir. Enzim inhibisyon sonuçlarına göre incelenen silisyum ftalosiyaninlerden DM-C3-Si kodlu bileşiğin bCA aktivitesi üzerine herhangi bir etkisi olmayıp inaktif bulunmuştur. DE-C3-Si 2333 nM'lık IC 50 değeri ile CA'nın en güçlü inhibitörleri arasında olan sülfanilamidden yaklaşık 2 kat daha yüksek inhibisyon etkisi göstermiştir. Bu değer ile DE-C3-Si bileşiği yeni potansiyel CA inhibitörleri sınıfları bulmak için kritik önem taşıdığını görülmektedir. Literatürde ftalosiyaninlerin farklı enzimler üzerine inhibisyon etkisi ile ilgili birçok çalışma vardır (Arslan ve ark, 2019; Demirbaş ve ark, 2019; Barut ve ark, 2017; Kantar ve ark, 2016). Fakat silisyum ftalosiyaninlerin CA enzimi üzerine inhibitör etkisi çalışmaları yeni yeni yapılmaktadır. Silisyum ftalosiyaninlerin karbonik anhidraz inhibitörleri olarak potansiyele sahip olduğunu ilk kez Arslan ve ark. (2018) tespit etmiştir (Arslan ve ark, 2018). 
Çizelge 1. Silisyum ftalosiyanin bileşiklerinin ve standartların bCA enzim inhibisyonu ve antioksidan aktivite sonuçları

\begin{tabular}{|c|c|c|c|}
\hline \multirow[b]{2}{*}{ Numune kodu } & Sığır karbonik anhidraz inhibisyon & \multicolumn{2}{|c|}{ Antioksidan aktivite } \\
\hline & $\mathrm{IC}_{50}(\mathrm{nM})$ & $\begin{array}{l}\text { DPPH・ temizleme } \\
\left(\mathrm{SC}_{50}, \mathrm{mg} \mathrm{mL}^{-1}\right)\end{array}$ & $\begin{array}{c}\text { FRAP }^{*} \\
(\text { TEAC, } \mu M)\end{array}$ \\
\hline DM-C3-Si & - & 0.0199 & 232 \\
\hline DE-C3-Si & 2333 & 0.0232 & 73 \\
\hline Troloks & T.E. & 0.0035 & T.E. \\
\hline BHT & T.E. & 0.0081 & T.E. \\
\hline C Vitamini & T.E. & 0.0295 & T.E. \\
\hline Sülfanilamid & 5000 & T.E. & T.E. \\
\hline
\end{tabular}

* FRAP, DM-C3-Si için $43.0 \mu \mathrm{M}$ ve DE-C3-Si $40.5 \mu \mathrm{M}^{\prime}$ 'a karş̧1lı gelen $0.04 \mathrm{mg} \mathrm{mL}^{-1}$ 'de test edildi, T.E.: test edilmedi.

Her yıl antibiyotik dirençli bakteriler nedeniyle tüm dünyada en az 700.000 ölüm gerçekleşmektedir. Eğer bu sorunun çözümlenmesi gecikirse, gelecekte tüm insanlığın kontrol edilemeyen antibiyotik direnci nedeniyle çok ağır bedeller ödeyeceği aşikardır (United, 2019). Son zamanlarda sentezlenen ftalosiyaninlerin antimikrobiyal aktivite göstermesi her geçen gün büyüyen bu sorunun çözümü için umut verici olmuştur (Nyamu ve ark, 2018). Bu çalışmada kullanılan DE-C3-Si ve DM-C3-Si kodlu silisyum ftalosiyaninler disk difüzyon metodu ile antibakteriyel aktivite açısından üç Gram-negatif ve üç Gram-pozitif bakteriye karşı test edilmiştir. Elde edilen test sonuçlarına göre, her iki bileşikte oldukça düşük antibakteriyel aktivite göstermiştir (Çizelge 2). Her iki bileşikte $0,01 \mathrm{mg} \mathrm{mL}^{-1}$, de aktivite göstermemekle birlikte, diğer dozlarda gösterdikleri antibakteriyel etki de birbirine çok yakındır. Ayrıca Gram-negatif ve Gram-pozitif bakterilere karşı gözlenen antibakteriyel aktiviteler arasında da dikkate değer bir farklılık yoktur. Tespit edilen antibakteriyel aktivitenin çok düşük olması, test edilen silisyum ftalosiyaninlerin çok büyük molekül yapısına sahip olmasına ve hücre membranından geçememiş olmasına bağlı olacağı düşünülmektedir (Nyamu ve ark, 2018). Ayrıca çalışılan bileşiklerin yüksek konsantrasyonlarda çökerek çözünmemesi, bu bileşiklerin yüksek konsantrasyonlarda çalışılabilmesini önlemiştir.

Çizelge 2. Çalışmada kullanılan silisyum ftalosiyaninlerin antibakteriyel aktivitesi

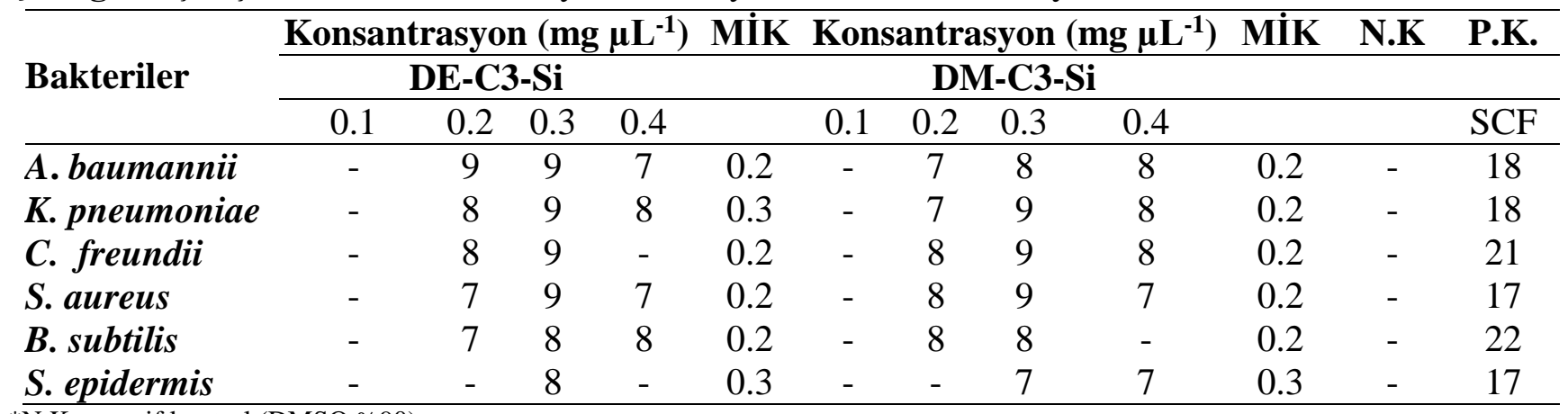

*N.K: negatif kontrol (DMSO \%90)

**P.K: pozitif kontrol: SCF $(30 \mu \mathrm{g} /$ disk $)$

***MIKK: minimum inhibisyon konsantrasyonu $\left(\mathrm{mg} \mu \mathrm{L}^{-1}\right)$

\section{SONUÇ}

$\mathrm{Bu}$ çalışmada elde edilen veriler silisyum ftalosiyanin bileşiklerinin önemini ortaya koymuştur. Öncelikli olarak ilaç potansiyeli olan yeni karbonik anhidraz inhibitörlerinin üretilebilmesinde yeni çalışmaların yapılması gerektiğini ortaya koymaktadır. Bu anlamda özellikle bileşikler arasında enzim inhibisyonu standart inhibitöre yakın olan DE-C3-Si bileşiği iyi bir başlangıç noktası olabilir. Ayrıca standart antioksidan olan C vitaminine kıyasla daha yüksek aktiviteleri nedeniyle de antioksidan ajanlar 
olabilme potansiyeline sahip oldukları gözlemlenmiştir. Ancak, bu bileşiklerin antibakteriyel aktivitelerinin göz ardı edilebilecek kadar düşük olduğu tespit edilmiştir.

\section{TEŞEKKÜR}

$\mathrm{Bu}$ çalışmanın test ve analizlerinin Espiye Meslek Yüksekokulundaki araştırma laboratuarlarında yapılmasına imkan sağlayan Giresun Üniversitesi'ne teşekkür ederiz.

\section{Çıkar Çatışması}

Makale yazarları aralarında herhangi bir çıkar çatışması olmadığını beyan ederler.

\section{Yazar Katkısı}

Yazarlar makaleye eşit oranda katkı sağlamış olduklarını beyan eder.

\section{KAYNAKLAR}

Agirtaş MS, Cabir B, Gümüş S, Özdemir S, Dündar A, 2018. Synthesis and Antioxidant, Aggregation, and Electronic Properties of 6-tert-butyl-1,4-benzodioxine Substituted Phthalocyanines. Turkish Journal of Chemistry. 42(1): 100-111.

Alterio V, DiFiore A, D’Ambrosio K, Supuran CT, De Simone, G, 2012. Multiple Binding Modes of Inhibitors to Carbonic Anhydrases: How to Design Specific Drugs Targeting 15 Different Isoforms?. Chemical Reviews.112(8), 4421-4468.

Armstrong JM, Myers DV, Verpoorte JA, Edsall JT, 1966. Purification and Properties of Human Erythrocyte Carbonic Anhydrase. The Journal of Biological Chemistry. 241(21): 5137-5149.

Arslan T, Biyiklioglu Z, Şentürk M, 2018. The Synthesis of Axially Disubstituted Silicon Phthalocyanines, Their Quaternized Derivatives and First Inhibitory Effect on Human Cytosolic Carbonic Anhydrase İsozymes hCA I and II. RSC Advances. 8: 10172-10178.

Arslan T, Çakır N, Keleş T, Biyiklioglu Z, Senturk M, 2019. Triazole Substituted Metal-Free, MetalloPhthalocyanines and Their Water Soluble Derivatives as Potential Cholinesterases Inhibitors: Design, Synthesis and in Vitro Inhibition Study. Bioorganic Chemistry. 90: 103100.

Barut B, Demirbaş Ü, Özel A, Kantekin H, 2017. Novel Water Soluble Morpholine Substituted Zn(II) Phthalocyanine: Synthesis, Characterization, DNA/BSA Binding, DNA Photocleavage and Topoisomerase I Inhibition. International Journal of Biological Macromolecules. 105(1): 499-508.

Basappa C, Reddy VKR, Kotresh HMN, Musturappa PK, Devendrachari MC, Ganesh SD, 2015. Synthesis, Characterization, Novel Interaction of DNA, Antioxidant and Antimicrobial Studies of New Water Soluble Metallophthalocyanines Posture Eight Hydroxyphenyl Moiety via 1,3,4oxadiazole Bridge. Journal of Heterocyclic Chemistry. 52(6): 1782-1791.

Bekaroğlu Ö, 1996. Phthalocyanines Containing Macrocycles. Applied Organometallic Chemistry. 10(8): 605-622.

Bıyıklığlu Z, Alp H, 2016. Synthesis, Characterization, Electropolymerization and Aggregation Properties of Axially Diethyl-dimethylaminophenoxypropanoxy Substituted Silicon Phthalocyanines and Their Water Soluble Derivatives. Dyes and Pigments. 132, 213-222.

Çelebi M, Ağırtaş MS, Dundar A, 2015. Different Peripheral Substituted Phthalocyanines: Synthesis, Characterization, Aggregation Behavior, Antioxidant and Antibacterial Activity. Journal of Structural Chemistry. 56(8): 1638-1645.

Cuendet M, Hostettmann K, Potterat O, Dyatmiko W, 1997. Iridoid glucosides with free radical scavenging properties from Fagrae ablumei. Helvetica Chimica Acta. 80(4): 1144-1152. 
Demirbaş Ü, Barut B, Yalçın İ, Değirmencioğlu İ, Yıldırmış S, Özel A, 2019. Synthesis, Characterization, and Investigation of Cholinesterase Inhibitory Properties of Novel Phthalocyanines. Journal of Heterocyclic Chemistry. 56(5): 1553-1559.

Demirkapi D, Şirin A, Turanli-Yildiz B, Çakar ZP, Sesalan BŞ, 2014. The Synthesis of New Silicon Phthalocyanines and Analysis of Their Photochemical and Biological Properties. Synthetic Metals. 187: 152-159.

Dini D, Barthel M, Schneider T, Ottmar M, Verma S, Hanack M, 2003. Phthalocyanines and Related Compounds as Switchable Materials Upon Strong Irradiation: the Molecular Engineering behind the Optical Limiting Effect. Solid State Ionics. 165: 289-303.

Efe D, 2019. The Evaluation of the Antibacterial Activity of Vetiveria zizanioides (L.) Nash Grown in Giresun. Alinteri Journal of Agriculture Science. 34(1): 3-4.

Efe D, 2020. Carbonic Anhydrase Enzyme Inhibition and Biological Activities of Satureja hortensis L. Essential Oil. Industrial Crops and Products. 156: 112849.

Farajzadeh N, Karaoglu HP, Akin M, Saki N, Koçak MB, 2019. Antimicrobial and Antioxidant Properties of Novel Octa-substituted Phthalocyanines Bearing (trifluoromethoxy) Phenoxy Groups on Peripheral Positions. Journal of Porphyrins and Phthalocyanines. 23: 91-102.

Günsel A, Alici EH, Bilgiçli AT, Arabaci G, Yaraşir MN, 2019. Antioxidant Properties of Water-Soluble Phthalocyanines Containing Quinoline 5-sulfonic acid Groups. Turkish Journal of Chemistry. 43: 1030-1039.

Günsel A, Bilgiçli AT, Kandemir C, Sancak R, Arabaci G, Yaraşır MN, 2020. Comparison of Novel Tetra-Substituted Phthalocyanines with Their Quaternized Derivatives: Antioxidant and Antibacterial Properties. Synthetic Metals. 260: 116288.

Kantar C, Mavi V, Baltaş N, Islamoğlu F, Şaşmaz S, 2016. Novel zinc(II) Phthalocyanines Bearing Azocontaining Schiff Base: Determination of pKa Values, Absorption, Emission, Enzyme Inhibition and Photochemical Properties. Journal of Molecular Structure. 1122: 88-99.

Karaçelik AA, Küçük M, Efe D, Çakır V, Bıyıklığlu Z, 2021. Carbonic Anhydrase Inhibition Potential and Some Bioactivities of the Peripherally Tetrasubstituted Cobalt(II), Titanium(IV), Manganese(III) Phthalocyanines. Letters in Drug Design \& Discovery. 18: E-pub Ahead of Print. Kluson P, Drobek M, Kalaji A, Zarubova S, Krysa J, Rakusan J, 2008. Singlet Oxygen Photogeneration Efficiencies of a Series of Phthalocyanines in Well-defined Spectral Regions. Journal of Photochemistry and Photobiology A: Chemistry. 199(2): 267-273.

McKenna R, Supuran CT, 2014. Carbonic Anhydrase Inhibitors Drug Design. Sub-cellular Biochemistry. 75: 291-323.

Nyamu SN, Ombaka L, Masika E, Ng'ang'a M, 2018. Antimicrobial Photodynamic Activity of Phthalocyanine Derivatives. Advances in Chemistry. 2018: 1-8.

Oyaizu M, 1986. Studies on Products of Browning Reactions: Antioxidative Activities of Product of Browning Reaction Prepared from Glucosamine. Japan Journal of Nutrition. 44(6): 307-315.

Pastarekova S, Parkkıla S, Pastorek J, Supuran CT, 2004. Carbonic Anhydrases: Current State of the Art, Therapeutic Applications and Future Prospects. Journal of Enzyme Inhibition and Medicinal Chemistry. 19(3): 199-229.

Sarkı G, Kantekin H, Yalazan H, Kahriman N, Biyiklioğlu Z, Serdaroğlu V, 2019. Synthesis, Characterization and Electrochemical Studies of Metal-free and Metallophthalocyanines Containing Two Different Chalcone Units Substituted on Peripherally Positions. Journal of Molecular Structure. 1196: 592-603. 
Supuran CT, 2010. Carbonic Anhydrase Inhibitors. Bioorganic \& Medicinal Chemistry Letters. 20(12): $3467-74$.

Supuran CT, Scozzafava A, 2007. Carbonic Anhydrases as Targets for Medicinal Chemistry, Bioorganic and Medicinal Chemistry. 15: 4336-4350.

Unluer D, Kamiloglu AA, Direkel S, Bektas E, Kantekin H, Sancak K, 2019. Synthesis and Characterization of Metallophthalocyanine with Morpholine Containing Schiff base and Determination of Their Antimicrobial and Antioxidant Activities. Journal of Organometallic Chemistry. 900: 120936.

United I, 2019. No Time toWait-Securing the Future from Drug-resistant Infections, Report to the Secretary General of the Nations. https://www.who.int/antimicrobial-resistance/interagencycoordination-group/final-report/en/ (Erişim Tarihi: 02.10.2020).

Ünlü S, Yaraşır MN, Kandaz M, Koca A, Salih B, 2008. Synthesis, Spectroscopy and Electrochemical Properties of Highly Soluble Fluoro Containing Phthalocyanines. Polyhedron. 27: 2805-2810.

Yıldırım N, Bilgiçli AT, Alici EH., Arabacı G, Yarasir MN, 2017. Formation, Characterization, Aggregation, Fluorescence and Antioxidant Properties of Novel Tetrasubstituted Metal-free and Metallophthalocyanines Bearing (4-(methylthio)phenoxy) Moieties. Journal of Molecular Structure. 1144: 66-79.

Yongde Y, Zhenguo J, 2006. Improved Photoreceptor Decay Characteristics of Vanadyl-phthalocyanine Films Annealed Under Magnetic Field. Journal of Photochemistry and Photobiology A: Chemistry. 179: 348-350.

Zhang L, Huang J, Ren L, Bai M, Wu L, Zhai B, Zhou X, 2008. Synthesis and Evaluation of Cationic Phthalocyanine Derivatives as Potential Inhibitors of Telomerase. Bioorganic and Medicinal Chemistry. 16(1): 303-312. 